\title{
O Ato "Responsivel", ou Mto Ético, em Bakhtin, e a Centralidade do Agente
}

\begin{abstract}
Adail SOBRAL
(FACIS - UNIMEP)

Resumo: Este artigo apresenta considerações acerca da maneira pela qual Bakhtin, em sua concepção do ato ético, ou ato "responsível", propõe e defende a centralidade do agente em sua relação ética com outros agentes, no contexto concreto da ação, como o cerne do agir humano. Com esse objetivo, percorre a obra Para uma filosofia do ato depois de situá-la em seu contexto histórico de surgimento, vital para a sua devida compreensão.

Palavras-chave: Bakhtin, dialogismo, filosofia do ato

Abstract: This paper discusses the way Bakhtin, in his conception of the ethical, or "responsable" (sic), act, proposes and argues for the centrality of the agent in her ethical relationship with other agents in the concrete context of action as the kernel of human agency. With this aim in view, the paper examines Bakhtin's work Towards a Philosophy of the Act, after presenting it from the perspective of his historical context of emergence, crucial for adequately understanding it.
\end{abstract}

Keywords: Bakhtin, dialogism, philosophy of the act

\section{Introdução}

Mikhail M. Bakhtin é hoje considerado um dos principais pensadores do século XX. Conhecido como teórico da literatura, da linguagem e do discurso e, mais recentemente (em especial fora do Brasil), como filósofo, esboçou entre 1920 e 1924 uma filosofia do ato ético que dialoga com uma multiplicidade de filósofos, de Aristóteles a autores do século XX (cf. SOBRAL, 2005c). Essa filosofia é conhecida como filosofia do ato, a partir do título dado a um de seus escritos fragmentados (e não preparados para publicação) pelo editor russo. Venho há alguns anos tentando demonstrar que das considerações aí 
feitas na juventude iria se desenvolver aquilo que hoje se conhece como dialogismo, fundado no chamado pensamento participativo, ou nãoindiferente (uchastnoye myshlenie), ou a idéia segundo a qual todo sujeito é constituído, forma sua identidade, sempre em processo, nas relações que mantém desde o nascimento com outros sujeitos, algo que é inclusive a base da concepção de cultura de Bakhtin e seu Círculo, na qual o sujeito ocupa uma inegável posição central.

Suas propostas se concentraram fortemente nas questões da linguagem e do discurso, tanto na vida diária como em sua representação literária, o que amplia o alcance de sua filosofia. Podemos considerálas as bases de uma filosofia da vida (Lebensphilosophie), ou seja, uma filosofia não transcendental - porque centrada no mundo concreto e não em princípios alheios a ela - nem imanente - porque centrada no agir dos sujeitos, mais no processo da ação do que em seus resultados. Suas propostas têm pontos de contato com a filosofia da vida de Henri Bergson (1859-1941) e com a filosofia do processo de Schelling (17751854), além de ter vínculos com teorias de Husserl, Merleau-Ponty e Heidegger, entre outras (cf. SOBRAL, 2005a). Além disso, fundam-se fortemente num proveitoso diálogo, sempre tenso, com neokantianos como Hermann Cohen (1842-1918) e principalmente com o próprio Immanuel Kant (1724-1804), de quem Bakhtin retomaria e reformularia radicalmente o conceito de arquitetônica (cf. SOBRAL, 2005b). Há ainda, entre outros elementos, concepções materialistas dialéticas que são retrabalhadas no que chamei de "síntese bakhtiniana" (em analogia com a célebre "síntese kantiana").

O primeiro aspecto a tornar complexa a tarefa de discorrer sobre conceitos de Bakhtin é o fato de as obras do Círculo terem sido elaboradas por vários autores numa época politicamente muito complicada na Rússia/União Soviética (os anos de Stálin), e não só para eles. Isso torna difícil inclusive estabelecer a real autoria dos escritos que chegaram até nós - e Bakhtin, tipicamente, nunca se empenhou em esclarecer essas questões; porque, embora defendesse e responsabilizasse radicalmente o sujeito individual, o pensador via esse sujeito como constituindo o ser dos outros e como constituído por eles. Por outro lado, a situação de produção desses escritos impediu a sistematização dos conceitos e noções, para não mencionar que Bakhtin tinha tanta paixão pelas diferenças e variações que costumava explicar de mais de um ponto de vista a mesma questão, chegando até a nomear a mesma coisa com mais de um nome. 
Para complicar a situação, as obras de Bakhtin e do Círculo não chegaram ao conhecimento dos estudiosos na ordem em que foram elaboradas; assim como obras mais recentes foram estudadas há várias décadas, algumas das primeiras só há alguns anos foram localizadas, editadas e traduzidas. Logo, uma tentativa de síntese poderia tanto seguir cronologicamente o percurso das obras, como, o que é mais interessante, centrar-se em seus pontos comuns, aqueles que se mantêm ao longo do tempo, sob várias perspectivas e em meio a reformulações, aqueles que permitem falar de um "pensamento bakhtiniano". Outro grande problema é o fato de os interesses de Bakhtin e seu Círculo serem extremamente amplos, cobrindo as mais diversas áreas: do uso oral da língua ao ato ético, da enunciação à estética, da literatura aos escritos íntimos, da ideologia à religião.

\section{Para uma filosofia do ato: o discurso fundador}

Para uma filosofia do ato (1920-1924) é uma espécie de programa de estudos, embora o primeiro texto de Bakhtin identificado seja Arte $e$ Responsabilidade (1919). Esse programa de estudos, que em grande parte foi realizado, ainda que não de maneira conclusiva, envolvia ao menos quatro questões filosoficamente relevantes. Em primeiro lugar, os atos humanos no mundo concreto (ou "a arquitetônica do mundo vivido" (SOBRAL, 2005a, p. 17)). Em segundo, o ato estético como agir ético (SOBRAL, 2005a, p. 17), ou seja, de como as obras de arte literária envolvem uma dimensão ética que impõe ao criador uma responsabilidade pela junção entre a vida concreta (o mundo vivido) e a criação artística (o mundo representado). Como veremos em "Autoria", sem que se confunda o autor empírico com o autor que se manifesta na obra. Esta proposta pode ser identificada em: a) "O autor e o herói” (anos 1920); b) "O problema do conteúdo, do material e da forma na criação verbal" (1924); c) "Discurso na Vida e Discurso na Arte" (1926; assinado por Voloshinov); e d) alguns fragmentos de Para uma Filosofia do Ato). Em terceiro lugar, a ética na política, que nunca foi abordada diretamente, embora se possam encontrar vestígios dela nos vários textos. Pode-se dizer que Bakhtin concebia a política em termos não-partidários e não institucionais, e muito menos coletivista, o que de resto explica os problemas políticos que o afetaram a ponto de ele ter sido exilado numa parte remota do território soviético. Por 
fim, a ética da religião, uma questão sempre presente para Bakhtin, inclusive ao tratar da questão da empatia e do amor como parte de suas concepções estéticas, como vemos em "O autor e o herói" (anos 1920) e nos apontamentos de 1970-1971, contidos em Estética da Criação Verbal.

Destaca-se em toda essa diversidade, e mesmo fragmentação, a unidade não das obras em si, mas da perspectiva a partir da qual se desenvolveram. Para ver a coerência das concepções de Bakhtin, é a meu ver suficiente atentar para um importante dado sobre sua unidade: um texto de 1974 (um ano antes da morte de Bakhtin), que trata de uma "metodologia das ciências humanas", retoma diretamente, desse ponto de vista, um esboço da década de 1940, remetendo ao texto depois denominado Para uma filosofia do ato, que é da década de 1920, e que se vincula não só a "Arte e Responsabilidade" (1919), como a "Discurso na vida e discurso na arte" (1926) - cada um com seu foco específico.

Assim, em meio a todos os percalços, variações, reestruturações e fragmentações, a obra como um todo, ainda que não exiba uma elaboração sistemática, é marcada por uma unidade de sentido, unidade configurada na idéia de que o mundo humano é um mundo de sentido, não um mundo material puro e simples, um mundo relacional, não um mundo de indivíduos autárquicos, um mundo de processos que envolvem sujeitos ímpares em interação e, portanto, um mundo que passa por constantes mudanças, mundo a que não se poderiam aplicar as leis da física, que são naturais, não humanas.

Bakhtin buscava entender a raiz dos fenômenos em vez de estabelecer de antemão a natureza de seus objetos de estudo, recusando tanto o positivismo da ciência ocidental da época (e não só dela), calcada nas ciências físicas, como o caráter mecânico da ciência comunista oficial, preferindo trilhar um perigoso caminho do meio, um caminho ético, que nada tinha de neutro, mas muito de imparcial, de dialético e, mais do que isso, de dialógico: nada do humano lhes foi estranho.

É preciso também esclarecer desde o começo que, ao contrário do que supõe a idéia comum de diálogo como espaço de harmonia, de compreensão mútua, diálogo na concepção de Bakhtin naturalmente não exclui uma possível harmonia ou compreensão mútua, mas é principalmente lugar de tensões (cf. AMORIM, 2003; SOBRAL, 2006), uma "arena de vozes" (VOLSHINOV, 1976a), um campo de 
luta, de confronto entre diferenças, estando seu aspecto principal no fato de que somos seres relacionais, seres que vivem e se constituem nas relações uns com os outros, que se formam nos diálogos que travam ao longo da vida.

\section{$2 \mathrm{O}$ ato ético}

Para mostrar a dissociação entre cultura e vida nas ciências humanas, Bakhtin afirma que:

O momento que o pensamento teórico discursivo (tanto nas ciências naturais como na filosofia), a descrição-exposição histórica e a intuição estética têm em comum, e que se reveste de particular importância para nossa investigação é: todas essas atividades estabelecem uma cisão fundamental entre o conteúdo ou sentido de um dado ato/ atividade e a concretude histórica do ser desse ato/atividade, a experiência atual e uni-ocorrente dele. É é em conseqüência disso que o ato dado vê-se privado de seu valor, bem como da unidade de seu vir-a-ser e de sua autodeterminação atuais

$[\ldots]$

$\mathrm{E}$, como resultado disso, dois mundos entram em confronto, dois mundos que não têm absolutamente nenhuma comunhão entre si e que são insensíveis um ao outro: o mundo da cultura e o mundo da vida, o único mundo em que criamos, aprendemos, contemplamos, vivemos nossa vida e morremos - ou o mundo em que os atos de nossa atividade são objetificados e o mundo em que esses atos se processam concretamente e são concretamente realizados uma só e única vez. Um ato de nossa atividade, de nossa experiência concreta, é como Jano, que tem duas faces. Ele olha em duas direções opostas: olha para a unidade objetiva de um domínio da cultura e olha para a uni-ocorrência nunca-repetível da vida atualmente vivida e experimentada. Mas não há um plano unitário e ímpar em que essas duas faces se determinariam mutuamente em relação a uma única unidade uni-ocorrente. É apenas o evento uni-ocorrente do Ser no processo de atualização que pode constituir essa unidade uniocorrente; tudo aquilo que tem caráter teórico ou estético tem de ser determinado como um momento constituinte no evento uniocorrente do Ser, embora não mais, é claro, em termos teóricos ou estéticos. Um ato tem de adquirir para si um plano unitário único a fim de ser capaz de refletir-se em ambas as direções - em seu sentido 
ou significado e em seu ser; tem de adquirir para si a unidade da responsibilidade bilateral - tanto para seu conteúdo (responsibilidade especial) como para seu Ser (responsibilidade moral). E a responsibilidade especial, além disso, tem de ser colocada em comunhão com a responsibilidade moral unitária e uni-ocorrente como um momento constituinte nela. Essa é a única maneira de se poder suplantar a perniciosa não-fusão e não-interpenetração de cultura e vida. (BAJTÍN, 1997a, p. 7-8 - tradução minha)

Dessa maneira, a filosofia do ato ético (ou ato "responsível" ou ato responsável) de Bakhtin é, em termos gerais, uma proposta de estudo do agir humano no mundo concreto, mundo social e histórico e, portanto, sujeito a mudanças, não apenas em termos de seu aspecto material, mas das maneiras de os seres humanos o conceberem simbolicamente, isto é, de o representarem por meio de alguma linguagem, e de agirem nesses termos em circunstâncias específicas. $\mathrm{O}$ empreendimento bakhtiniano sobre essa questão consiste em tentar mostrar como generalizar acerca das singularidades que são os atos sem perder de vista sua singularidade nem a generalidade!

Falar de ato é falar de um agir geral que engloba os atos particulares; por isso, falar de ato é falar ao mesmo tempo de atos. O ato como conceito é o aspecto geral do agir humano, enquanto os atos são seu aspecto particular, concreto. Todos os atos têm em comum alguns elementos: um sujeito que age, um lugar em que esse sujeito age e um momento em que age. Isso se aplica tanto aos atos realizados na presença de outros sujeitos como aos atos realizados sem a presença de outros sujeitos, aos atos cognitivos que não tenham expressão lingüística etc. Fazê-lo pressupõe, portanto, dois planos inter-relacionados: um plano de generalidade, o dos atos em geral, e um plano de particularidade, de cada ato particular. Como se sabe, a generalidade e a particularidade são categorias filosóficas, e o filósofo Bakhtin as considera em sua proposta de filosofia do ato; ele distingue entre o conteúdo do ato, isto é, aquilo que o ato produz ao ser realizado, ou seu produto, e o processo do ato, ou seja, as operações que o sujeito realiza para produzir o ato.

Vemos na concepção de ato de Bakhtin um processo do ato, um produto do ato e um agente do ato. Ao contrário de algumas filosofias da ação, ou do processo, a filosofia de Bakhtin pode ser considerada, 
como já afirmei, uma "filosofia humana do processo", ou seja, uma filosofia do processo em que o agente do processo, e não apenas o processo, tem sua importância reconhecida. Do mesmo modo, ao contrário de outras filosofias, de caráter mais formalista, vinculado com a forma (ou de caráter mais teorético), o produto do ato, ou o aspecto comum a todos os atos, não é o elemento mais importante. Isso acontece porque, para Bakhtin, a vida, o mundo concreto, é a vida de sujeitos concretos, é vida prática, e seu entendimento pela teoria não pode por isso ser abstrato, ou seja, tão geral que perca de vista os atos concretos realizados por sujeitos concretos em situações concretas que as teorias não podem abarcar de uma vez por todas.

Além disso, ele concebe a vida de cada sujeito como formada de uma sucessão de atos concretos; trata-se de atos que são singulares, irrepetíveis (só acontecem uma vez), atos únicos, ou atos que não são iguais a outros atos, mas que têm elementos comuns com outros atos e por isso fazem parte do ato como categoria englobante. Bakhtin critica várias teorizações, filosóficas e outras, que, ao generalizar, apagam a especificidade de cada ato, vendo apenas o que há de comum entre eles; é o que Bakhtin denomina "teoreticismo", ou a tendência a perder de vista, ao se criarem conceitos, o aspecto concreto, material, dos eventos que servem à formação dos conceitos.

Ao ver do filósofo, é nefasta a tendência teoreticista de reduzir atos particulares ao que há em comum entre todos os atos, pois isso separa o concreto do abstrato, o geral do particular, e, assim, perde de vista a totalidade que é o ato, uma dialética entre conteúdo (ou sentido) e processo concreto de realização. Bakhtin se opõe aqui a filosofias formalistas, próximas do racionalismo, em que as categorias de organização da percepção se sobrepõem ao aspecto empírico da percepção e a reduzem ao geral.

Por outro lado, ao defender uma versão da filosofia da práxis materialista dialética, Bakhtin evita cuidadosamente cair no extremo oposto de certas tendências filosóficas, próximas do empirismo, em que a percepção seria tida como imediata, sem categorias que a organizem, e que a reduzem assim a seu aspecto particular. Logo, se não admite que a teoria apague a vida concreta, prática, Bakhtin também não admite que a prática concreta apague a teoria, o plano em que se pode generalizar sobre todos os atos. 
Nesse sentido, Bakhtin considera vital, em todo empreendimento humano, evitar a separação entre "o conteúdo ou sentido de um dado ato/atividade e a concretude histórica do ser desse ato/atividade, a experiência atual e uni-ocorrente dele" (BAKHTIN, 1993, p. 1), separação que a seu ver atinge tanto o pensamento teórico discursivo (as ciências naturais e na filosofia) como a descrição-exposição histórica e a intuição estética. O "conteúdo ou sentido do ato/atividade" refere-se ao produto do ato, aquilo que o ato gera; a "experiência atual e uni-ocorrente" do ato é o processo do ato, que se atualiza (se realiza) numa situação concreta que não permanece imutável e, portanto, ocorre uma única vez.

Ainda que realize a mesma ação física (Tat, do alemão filosófico) e o mesmo ato puro ( $A k t$ ) ao agir no aqui e agora (e só se age no aqui e agora), o sujeito terá realizado segundo Bakhtin dois atos (Akt-deiatel'nost) distintos, pois a ação física e o ato puro são partes do conteúdo do ato, mas não de sua experiência concreta, que não se repete, ainda que as circunstâncias de sua realização se assemelhem. Trata-se de uma dialética "produto-processo"; dialética porque o processo supõe um produto dele resultante e o produto, um processo de produção.

A partir dessa dialética dialógica, embora os diferentes atos possam ser objeto de uma generalização como atos, membros da classe do ato, dado que o conteúdo ou sentido de cada ato é repetível, ocorre mais de uma vez, seu processo, por ser irrepetível, ocorrer uma só vez, não pode ser objeto de uma generalização. Assim, entender um ato é entender o todo do ato, sua dialética produto-processo, seu caráter situado, isto é, de ação humana que ocorre num bic et nunc, aqui e agora.

\section{$3 \mathrm{O}$ ato, o sensível e o inteligível}

Bakhtin traz assim à luz para os fins de sua filosofia da vida outra importante distinção filosófica, a que separa o sensivel do inteligivel. O sensivel está ligado ao mundo da vida (Lebenswelt), ao mundo vivido, e é o plano das impressões que o sujeito obtém de suas vivências nesse mundo dado, mundo existente per se; refere-se, no caso da teoria do ato, ao vir-a-ser concreto do ato, ao seu processo. O inteligível está ligado à elaboração segunda da percepção, ou seja, à apreensão 
organizada das impressões (em nosso caso, do sentido ou conteúdo do ato), apreensão em termos de dada forma de organização, referindose à parcela generalizável do(s) ato(s). Por conseguinte, integram-se nos atos o conteúdo e a forma, a materialidade concreta e a elaboração teórica, o estar-no-mundo e a categorização do mundo, os elementos peculiares a cada ato e o que de comum existe entre todos os atos. Bakhtin privilegia sempre a situação concreta em que ocorrem os atos.

Ele afirma que se pode fazer abstração do produto ou do processo, por razões teóricas e outras, mas não se pode tomar nem o produto nem o processo como a totalidade do ato. Fazê-lo é cair seja no teoreticismo que nega o diferente ou num tosco empirismo que só vê o diferente. Afinal, o conteúdo, ou aspecto abstrato do ato, que todo ato e cada ato compartilha com todos os outros atos, é organizado com base no processo do ato, no agir do sujeito em sua situação histórica e social, e o processo do ato, ou aspecto concreto do ato, que é peculiar de cada ato, só pode ser compreendido a partir da estrutura compartilhada por todos os atos.

O plano das categorias de organização da experiência humana, ou inteligível, e o plano das experiências humanas, ou sensível, plano da percepção das impressões totais, só adquirem sentido em sua oposição complementar, em sua dialética: a percepção sensível da multiplicidade e a redução inteligível à unidade são "instâncias" separáveis teoricamente, mas que se auto-pressupõem na prática: uma não existe sem a outra, e sua articulação é que permite identificar o ato como um todo. Nisso Bakhtin se aproxima da redução fenomenológica de Husserl e Merleau-Ponty, o retorno às "coisas mesmas", ao mundo vivido, o Lebenswelt, mas insiste em tomá-lo em seu aspecto contextual e situacional, sem abstrações teoreticistas.

O mundo dado, o mundo que está aí (dan em russo), mundo sensível, se articula com o mundo postulado (zadan), o mundo organizado, mundo inteligível, ou, de outro ponto de vista, o mundo da realização (processo) de uma multiplicidade de atos irrepetíveis, o mundo das singularidades que são os atos, se articula com o mundo da organização (sentido) da multiplicidade de atos irrepetíveis, mundo da unidade, da generalidade, que é o conceito de ato. Esta é a maneira encontrada por Bakhtin para generalizar sobre as singularidades que são os atos humanos, que não seguem leis como as da física, por exemplo, leis que supõem a eterna repetibilidade do ato. 


\section{Ato e agente}

O ponto alto da proposta de Bakhtin sobre o ato são os agentes, os sujeitos concretos que realizam atos. Não há para Bakhtin teorização sobre o ato sem referência aos sujeitos, nenhuma "semântica da ação sem agentes" (RICOEUR, 1990, p. 73). Logo, o grande diferencial da filosofia do ato de Bakhtin é precisamente a forma de proposição do agente dos atos como mediador entre os atos particulares que realiza e os atos/atividades possíveis em sua situação concreta, a estrutura e as nuanças conjunturais que assumem as práticas no âmbito das quais o agente realiza atos. Bakhtin entende o ato, já ao escolher a palavra russa com que o designa, postupok, como "ato-feito", "ato-façanha", logo, ato em processo de realização, nunca ato acabado, estiolado, distante da vida concreta dos sujeitos.

Temos como principais implicações disso que (a) o agente age numa situação concreta organizada em torno de práticas sociais e históricas que limitam as possibilidades de atos e de formas de realização de atos e (b) essas circunstâncias específicas devem ser consideradas em todo entendimento de atos. As práticas sociais, vinculadas com as esferas de atividade, supõem necessariamente grupos humanos, e não sujeitos isolados. Supõem igualmente situações concretas e sujeitos concretos. Supõem ainda a intencionalidade do sujeito de realizar atos e sua realização concreta de acordo com formas aceitas de realização, mesmo nos casos em que uma sucessão de atos, seguindo essas normas, desemboca na alteração dessas mesmas normas (o aspecto estáticodinâmico de todo agir humano).

Para Bakhtin, que fala dos atos realizados segundo a atividade que cada sujeito desempenha (pode desempenhar) no mundo concreto em que vive, há atividades-tipo, ou atos/atividades, definidas como conjuntos globais de atos, e atos-ocorrência, ou atos/feitos, definidos com ocorrências singulares de atos, organizados contudo segundo atos/ atividades, mas que podem alterar a estrutura desses mesmos atos atividades. Esclareço que não estão excluídos da categoria dos atos as ações involuntárias dos sujeitos, mas destaco que o foco aqui é a categoria de sujeito entendida em termos éticos, em termos de responsabilidade ética e de responsividade ética aos outros sujeitos. Para Bakhtin, "não há álibi na existência", e os atos do sujeito, sejam ou não voluntários, são responsabilidade sua, ou melhor, "responsıbilidade" sua, isto é, 
responsabilidade pelo ato e responsividade aos outros sujeitos no âmbito das práticas em que são praticados os atos (cf. SOBRAL, 2005a, p. 2021).

Bakhtin, aproximando-se de Sartre e Heidegger, reformula o "em-si" e o "para-si" hegelianos em termos da condição humana segundo as categorias "eu-para-mim", "eu-para-o-outro" e "outropara-mim". O eu-para-mim é, naturalmente, o eu enquanto voltado para si mesmo; o "eu-para-o-outro" se refere à iniciativa do sujeito de aproximar-me de outros sujeitos, numa espécie de "saída de si"; e o "outro-para-mim" se refere à iniciativa do outro de aproximar-se do eu, também uma espécie de "saída de si". Tentando, como é típico de seu pensamento, alcançar a unidade do fenômeno em vez de limitar-se a algum aspecto parcial dele, Bakhtin considera legítimo que o eu saia de si para aproximar-se do outro, e vice-versa, mas afirma enfaticamente que essa saída deve ser sempre seguida de uma "volta a si": aquele que se põe no lugar do outro e não volta ao lugar que lhe pertence é infiel a si e ao outro! Porque cada sujeito ocupa um lugar ímpar, irrepetível, insubstituível no mundo. Logo, as relações entre sujeitos não submetem os sujeitos, singulares, ao coletivo de sujeitos, despersonalizando-os, e ao mesmo tempo não atribui a cada sujeito a possibilidade de se sobrepor ao coletivo, tornando-se autárquico.

Assim, Bakhtin exige coerentemente de cada sujeito a responsabilidade por seus atos e obrigações éticas com relação aos outros sujeitos. E o faz propondo o que chamei de "sujeito situado" (SOBRAL, 2005a, p. 22 e seguintes), um sujeito cujas decisões éticas não ocorrem a partir de regras gerais aplicáveis a todas as situações, mas da junção entre essas regras e as circunstâncias específicas da decisão. Em vez de um código moral, um conjunto de regras abstratas, ele propõe um sistema ético, um conjunto que parte de regras abstratas e as torna concretas nas situações em que se tomam decisões éticas. $\mathrm{O}$ sujeito que toma decisões éticas, e ele as toma em suas circunstâncias específicas, não pode alegar depois que foi vítima delas (naturalmente, exceto em caso de uma coação irresistível), nem pode culpar as regras gerais pelo desfecho de suas decisões concretas específicas. Porque o conteúdo ou sentido das decisões éticas está intrinsecamente ligado ao processo de decisão e, portanto, à "situacionalidade" do agente. Essa formulação tem implicações para a concepção de linguagem de Bakhtin, algumas das quais discuto bem brevemente a seguir. 


\section{Ato e Dialogismo: algumas implicações}

Não há nem primeira palavra nem derradeira palavra. Os contextos do diálogo não têm limite. Estendem-se ao mais remoto passado e ao mais distante futuro. Até significados trazidos por diálogos provenientes do mais longínquo passado jamais hão de ser apreendidos de uma vezpor todas, pois eles serão sempre renovados em diálogo ulterior. ... Pois nada é absolutamente morto: todo significado terá algum dia o seu festival de regresso ao lar.

BAKHTIN

Os atos humanos ocorrem, segundo a filosofia de Bakhtin e seu Círculo, em permanente tensão com outros atos, passados e futuros, ou seja, o dialogismo é a base da idéia de que só da diferença nasce o sentido, sem menosprezar a semelhança, porque, sem esta última, haveria incompatibilidade, não diferença. Essa concepção vê a diferença não como propriedade de um sistema (ou código) fechado, mas como a base e o resultado das relações concretas entre os seres humanos na sociedade e na história, relações que apresentam elementos estáveis, que se repetem, e elementos instáveis, que não se repetem; uns não existem sem os outros.

Os elementos estáveis são justamente os que nos permitem identificar os elementos instáveis; esses elementos instáveis, por sua vez, acabam por alterar os estáveis, criando um novo estado do sistema. Como isso ocorre o tempo inteiro, nunca há um sistema estático, mas um constante processo de interconstituição entre estabilidade e mudança que faz desse sistema, por paradoxal que possa parecer, um dinamismo que integra os elementos constantes que fazem dele um sistema na formação de uma nova totalidade maior do que a soma de suas partes.

Cabe reenfatizar, embora possa parecer desnecessário, que "dialogismo" não se confunde com "diálogo", sejam as réplicas de um diálogo face a face ou sua representação em discursos, estéticos e outros. O diálogo é um fenômeno textual e um procedimento discursivo englobado pelo dialogismo, sendo apenas um de seus níveis mais evidentes no nível da materialidade discursiva. Por outro lado, o enunciado e o discurso, por mais "fechados", por mais "subjetivos" que sejam, continuam a ser dialógicos, porque, resumidamente, (1) não pode haver enunciado sem sujeito enunciador; (2) nenhum sujeito 
pode agir fora de uma interação, mesmo que o outro não esteja fisicamente presente; (3) não há interação sem diálogo; e (4) a interação é uma relação entre mais de um sujeito, mesmo no caso do "discurso interior".

Pode-se assim dizer que a "concepção dialógica da linguagem" é qualificada como dialógica porque propõe que a linguagem (e os discursos) têm seus sentidos produzidos pela presença constitutiva da intersubjetividade (a interação entre subjetividades) no intercâmbio verbal, ou seja, nas situações concretas de exercício da linguagem, dos atos de linguagem. A intersubjetividade é entendida em termos psíquicos, sociais e históricos, em vez de puramente psicológicos, e é considerada, como corolário, a condição de possibilidade da subjetividade, também ela de caráter psíquico, social e bistórico: o sujeito da linguagem, sujeito do discurso, é um agente - ou melhor, um "interagente" -, alguém que age na presença, mediata ou imediata, de outro(s) agente(s).

Por conseguinte, o conceito de dialogismo, vinculado indissoluvelmente ao de interação, é a base do processo de produção dos discursos e, o que é mais importante, da própria linguagem: para o Círculo, o locutor e o interlocutor têm o mesmo peso, porque toda enunciação é uma "resposta", uma réplica, a enunciações passadas e a possíveis enunciações futuras, e ao mesmo tempo uma "pergunta", uma "interpelação" a outras enunciações: o sujeito que fala o faz levando o outro em conta não como parte passiva mas como parceiro colaborativo ou hostil - ativo. A linguagem para o Círculo define-se precisamente a partir dessa cadeia ou corrente mutante de enunciações, de enunciados concretos, de atos, sempre concretos, de linguagem.

\section{Conclusão}

Para Bakhtin, ser "responsível" supõe mostrar-se diante do outro como alguém que assume necessariamente a responsabilidade por aquilo que fala/faz, e nesse plano o sujeito "assina" aquilo que diz/faz, pois embora todo ato seja social em dado aspecto, sendo portanto repetível, no outro todo ato é individual, irrepetível, porque nunca ocorre da mesma maneira que outros atos: cada sujeito realiza o "mesmo" de "outra" maneira, de maneira sua, sem que com isso deixe de se alterar no contato com o outro e sem que os atos únicos que realiza sejam tão diferentes que não tenham elementos em comum 
com outros atos a ponto de não serem reconhecidos como atos do universo de atos possíveis e compreensíveis.

O que mais merece destaque nessa concepção é justamente o papel ativo do sujeito, seu caráter de agente, dado ser essa sua condição que une pessoal e social, cognitivo e empírico, universal e singular, em atos que apresentam um conteúdo (ou produto) que remete aos de outros atos, mas cujo processo é sempre único, ímpar, singular. Portanto, no sujeito está o mundo, do mesmo modo como o sujeito está no mundo: o ato do sujeito altera o mundo em que o sujeito está e esse sujeito também é alterado por esse mundo. Claro que isso envolve diferentes proporções: nem todo sujeito pode dizer/fazer determinadas coisas, pois isso depende de seu lugar social, seu papel na sociedade, em seu grupo social, em seu ambiente familiar e profissional etc., em que ele ocupa diferentes "posições-sujeito", suas possibilidades sócio-históricas de ação como sujeito, que mudam ao longo da vida e das circunstâncias.

Logo, a valoração/avaliação ética que o agente tem de fazer de seus próprios atos é o elemento unificador de todos os atos de sua atividade. Trata-se de um ato de avaliação "responsível" em que se fazem presentes o processo do ato, ou sua singularidade, o conteúdo do ato, ou sua generalidade, e o agente como sujeito que avalia seus atos/ feitos singulares no âmbito da generalidade dos atos/atividades. $O$ sujeito não está sozinho: o valor de seus atos, a avaliação/valoração que o sujeito faz deles é o valor que eles têm para o agente, em vez de um valor absoluto que se impusesse a ele, mas cabe insistir que essa valoração/avaliação ocorre numa situação de interação com outros sujeitos.

O sujeito une em seus atos éticos, em suas decisões éticas, o mundo dado (dan), mundo natural, e o mundo postulado (zadan), social e histórico, objetivado, ou "interpretado", por uma coletividade, mas o faz em seus próprios termos, pelos quais tem de responsabilizar-se. $\mathrm{O}$ agir do sujeito, assim, é uma sucessão de atos de mediação entre o geral e o particular; essa mediação tem um caráter situado, avaliativo e responsável, nos termos da situação do sujeito, entre a materialidade concreta e a "simbolização" coletiva dessa materialidade. Trata-se de uma mediação que depende da apropriação específica que cada sujeito, singular que é, faz pessoalmente da "interpretação" (objetivação) coletiva do mundo dado. 
O ponto alto da teoria do ato de Bakhtin, que engloba suas outras teorias, é por conseguinte a defesa da idéia de que a validade das decisões do sujeito (que são sempre éticas, inclusive apesar dele mesmo) depende não de abstrações, mas da articulação, junção, entre regras éticas (se assim se pode dizer) e as circunstâncias concretas da vida concreta, do processo situado de decisão, do agente: o sujeito, ao agir, deixa por assim dizer uma "assinatura" em seu ato e por isso tem de responsabilizar-se pessoalmente por seu ato e se responsabiliza por ele perante a coletividade de que faz parte - e, em última análise, perante a humanidade como um todo!

Em conseqüência, para a concepção do ato ético de Bakhtin, agir é sempre comprometer-se, agir é sempre ser interpelado pelo outro do ponto de vista ético, agir é sempre ser chamado à responsabilidade e à responsividade. Porque não há atos isolados nem atos abstratos, assim como não há atos pelos quais o sujeito possa não se responsabilizar, ainda que the seja dado justificar-se por seus atos/ justificar seus atos. Portanto, o próprio ato de pensar de si para si é já um compromisso com as circunstâncias do sujeito, dos outros sujeitos e da situação concreta em que os dois (ou mais) interagem, e é já um comprometimento do sujeito com a responsabilidade e a responsividade que dele se espera e que ele espera dos outros.

\section{Referências}

AMORIM, M. O pesquisador e seu outro. Bakhtin nas Ciências Humanas. São Paulo: Musa, 2001.

BAJTIN, M. M. Estética da criação verbal. 4. ed. Trad. Paulo Bezerra. São Paulo: Martins Fontes, 2003 [1920-1974]. [Nova edição com tradução a partir do russo].

. Estética da criação verbal. 2. ed. Trad. M.H. Galvão. São Paulo: Martins Fontes, 1997a [1920-1974]. [Tradução feita a partir da edição francesa].

. Hacia uma filosofia del acto ético. De los borradores y otros escritos. Trad. e notas: Tatiana Bubnova. Barcelona/San Juan: Anthropos/ EDUPR, 1997b [1920-1924]. 
Problemas da poética de Dostoievski. 2. ed. Trad.: Paulo Bezerra. São Paulo: Forense-Universitária, 1997c [1929].

Questões de literatura e de estética (Teoria do Romance). 3. ed. Trad.: A. F. Bernadini et al. São Paulo: UNESP, 1993 [1975].

The dialogic imagination: four essays. Org. Michael Holquist; Trad. Caryl Emerson e Michael Holquist. Texas: University of Texas Press, 1981.

BAKHTINE, M. (Década de 1930/1965). L'oeuvre de Francois Rabelais et la culture populaire au Moyen Age et sous la Renaissance. Trad. Andrée Robel. Paris: Gallimard, 1970.

RICOEUR, P. Soi-même comme un autre. Paris: Seuil, 1990.

SILVESTRI, Adriana; BLANCK, Guilhermo. La construcción de la enunciación. [1929]. In:______.; ______. Bajtín y Vigotski: la organización semiótica de la conciencia. Barcelona: Anthropos, 1993. p. 245-276.

;_ ¿ ¿ ¿Qué es el lenguaje? [1929]. In: ;

Bajtín y Vigotski: la organización semiótica de la conciencia. Barcelona: Anthropos, 1993, p. 217-243.

SOBRAL, A. U. Elementos sobre a formação de gêneros discursivos: a fase "parasitária" de uma vertente do gênero de auto-ajuda. 2006. 324p. Tese (Doutorado em Lingüística Aplicada e Estudos da Linguagem) LAEL/PUC-SP, São Paulo.

. Ato/atividade e evento. In: BRAIT, B. Bakbtin: conceitoschave. São Paulo: Contexto, 2005a. p. 11-36.

Ético e estético - na vida, na arte e na pesquisa em Ciências Humanas. In: BRAIT, B. Bakbtin: conceitos-chave. São Paulo: Contexto, 2005b. p. 103-121. 
Filosofias (e filosofia) em Bakhtin. In: BRAIT, B. Bakbtin: conceitos-chave. São Paulo: Contexto, 2005c. p. 123-150.

VOLOSHINOV, V. N. Más allá de lo social. Ensayo sobre la teoría freudiana. In: SILVESTRI, Adriana; BLANCK, Guilhermo. Bajtin y Vigotski: La organización semiótica de la conciencia. Barcelona: Anthropos, 1993 [1925].

El signo ideológico y la filosofía del lenguaje. Trad. Rosa María Rússovich. Buenos Aires: Nueva Visión, 1976a [1930].

Frendism. Trad. I. R. Titunik. New York: Academic Press, 1976b [1927]. 